\title{
Monitoring the New Antithrombotic Drugs
}

\author{
Jeanine M. Walenga, Ph.D., and Debra A. Hoppensteadt, Ph.D.
}

In the above-mentioned article, published in Seminars in Thrombosis and Hemostasis 2004; Volume 30, Number 6, Fig. 10 on page 692 is incorrect. The curves in the figure are mislabeled and should be interchanged such that fondaparinux is represented by the box and DX-9065a by the ellipse. The correct figure is given below.

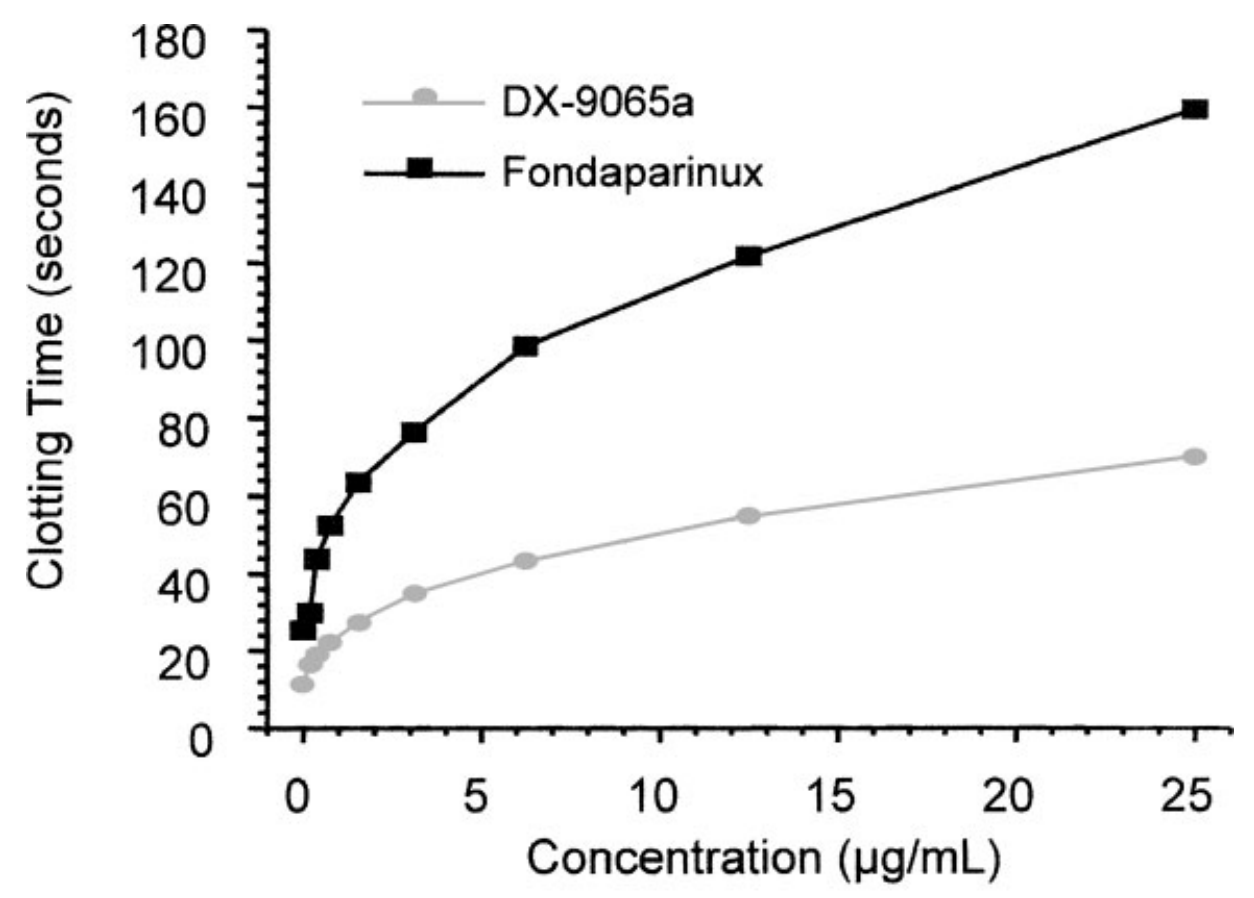

Figure 10 Factor Xa inhibitors have varying responses in the clot-based anti-factor Xa assay (Heptest, Haemachem). The heparin pentasaccharide fondaparinux produces a dose-dependent linear response, whereas the Heptest is insensitive to the direct inhibitor DX9065a.

Current Development in Antithrombotic Therapy; Editor in Chief, Eberhard F. Mammen, M.D.; Guest Editors, Judith C. Andersen, M.D., Syed M. Jafri, M.D., Scott Kaatz, D.O., and Jawed Fareed, Ph.D. Seminars in Thrombosis and Hemostasis, volume 30, number 6, 2004. Address for correspondence and reprint requests: Dr. Jeanine. M. Walenga, Cardiovascular Institute, Loyola University Medical Center, 2160 S. First Avenue, Maywood, IL 60153. E-mail: jwaleng@lumc.edu. ${ }^{1}$ Departments of Thoracic and Cardiovascular Surgery and Pathology, Loyola University Medical Center, Maywood, Illinois. Copyright (C) 2004 by Thieme Medical Publishers, Inc., 333 Seventh Avenue, New York, NY 10001, USA. Tel: +1(212) 584-4662. 0094-6176,p;2005,31,02,247,247,ftx,en;sth01051x. 